\title{
Proximal Extra-articular Tibial Fractures Associated with Soft-tissue Impairment in Geriatric Patients: Definitive Treatment by Hybrid External Fixation
}

\author{
Yoann Durand ${ }^{*}$, Franziska Kocher, Moritz Tannast, Daniel Petek \\ Clinic of Orthopaedics and Trauma Surgery, Fribourg District Hospital, Fribourg, Switzerland
}

Email address:

Yoann.durand@h-fr.ch (Y. Durand)

${ }^{*}$ Corresponding author

\section{To cite this article:}

Yoann Durand, Franziska Kocher, Moritz Tannast, Daniel Petek. Proximal Extra-articular Tibial Fractures Associated with Soft-tissue Impairment in Geriatric Patients: Definitive Treatment by Hybrid External Fixation. Journal of Surgery. Vol. 9, No. 2, 2021 , pp. 82-85. doi: $10.11648 /$ j.js.20210902.18

Received: March 5, 2021; Accepted: March 29, 2021; Published: April 7, 2021

\begin{abstract}
Fractures in the elderly population are a major increasing issue for any healthcare institution, associated with the growing life expectancy. Proximal tibial fractures affect the metaphyseal bone with or without articular extension, in 5 to $11 \%$ of all tibia fracture. Treatment options such as plate fixation, intramedullary nailing or even primary total knee arthroplasty are accepted valuable options. However, specific age-related risk factors such as osteoporosis, arthritis, multiple comorbidities and soft-tissue impairment shall also be taken in consideration as they may lead to severe complications if not fully understood. Therefore, a hybrid tibio-tibial external fixator may be considered as a valid surgical option for primary and definitive treatment care of these fractures especially if associated with soft-tissue damage. We report a retrospective observational analysis of three cases of closed extra-articular proximal tibia fractures associated with soft-tissue impairment in a geriatric population and treated with a hybrid external fixator (TenXor, Stryker). The fractures were classified according to the AO, as metaphyseal fractures (AO 41A2.1, 41 A3.3). The post-operative protocol was standardized, with immediate full weight bearing. Complete consolidation of the fractures was obtained at 6 months. There were no pin tract infection and removal of the material has been done at 6 months. No cut-out of the proximal tibial wires was observed. The primary and definitive care of proximal tibial fractures by a hybrid external fixator appears to be a valuable surgical option in geriatric patients especially when associated with poor soft tissue coverage. The major advantage of this technique, acknowledging the longer bone consolidation process, is to avoid additional insult to the soft tissues. This surgical option gathers further treatment perspectives in the elderly population especially in cases of soft tissue limitations.
\end{abstract}

Keywords: Proximal Tibial Fracture, Metaphyseal Fracture, Geriatric Trauma, Soft-tissue Impairment

\section{Introduction}

The management of fractures in the elderly population is currently becoming a major public health issue, given the increasing life expectancy [1]. Fractures of the proximal tibia account for only 5 to $11 \%$ of all tibia fractures [2]. These are typically epiphyseal, including intra-articular extension, or metaphyseal, which are much less common [3]. In the geriatric population, commonly defined as 65 years of age and older [4], the fracture mechanism is usually a simple fall from own height [5]. Because of concomitant adjacent soft tissue compromise, the treatment of such fractures remains a challenge, and no single treatment has to date been identified as a gold standard [6-8]. The standard treatment options for these fractures include intramedullary nailing or plate osteosynthesis [6]. Even if less applied, the implantation of a primary total knee replacement is also an option, providing acceptable functional result [9]. However, all these techniques can lead to severe complications, especially in elderly people with multiple comorbidities and specific risk factors, such as soft-tissue fragility or osteoporosis [10, 11]. Osteoporosis affects $6.6 \%$ of men and $22.1 \%$ of women aged over 50 years in the EU, according to the report of the International Osteoporosis Foundation [12]. 
We report a clinical series of three geriatric patients admitted for fractures of the proximal tibia associated with soft tissue impairment, treated with hybrid tibio-tibial external fixator as a definitive treatment.

\section{Case Presentation}

Three patients, two males and one female, mean age of 83 years, were admitted in the emergency ward, one after suffering from a road accident and the other two after a fall from own height (Table 1).

Table 1. Baseline characteristics of the patients and fracture classifications.

\begin{tabular}{llll}
\hline & Patient 1 & Patient 2 & Patient 3 \\
\hline Gender & Male & Male & Female \\
Age (years) & 85.8 & 78.6 & 84.7 \\
ASA score & III & III & III \\
Fracture location & Metaphyseal & Metaphyseal & Metaphyseal \\
AO classification & $41 \mathrm{~A} 2.1$ & $41 \mathrm{~A} 3.3$ & $41 \mathrm{~A} 3.3$ \\
Tscherne classification & C2 & C1 & C2 \\
\hline
\end{tabular}

All patients had an ASA score of III. One patient had an associated fracture of the ipsilateral proximal humerus that was treated conservatively. Another patient had a Lisfranc lesion on the contralateral foot, also without indication for surgical treatment. All the tibial fractures were closed, metaphyseal, graded 41A2.1 and 41A3.3 according to the AO system [13] (figure 1a-b, figure 2a-b). Assessment of the soft tissue envelope has been done according to the Tscherne classification. The classification adresses soft tissues from grade C0 (little or no soft tissue damage) to grade $\mathrm{C} 3$ (extensive skin contusion, myonecrosis, degloving, vascular injury or compartment syndrome) $[14,15]$.

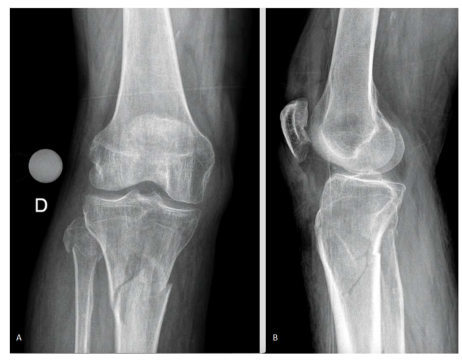

Figure 1. $a$ - $b$ : Emergency X-rays, patient 1.

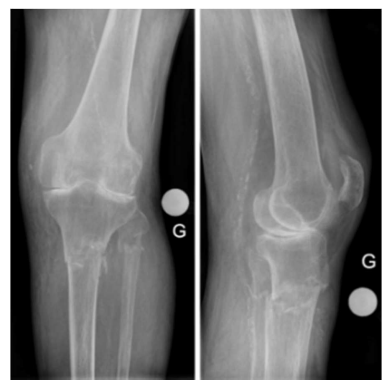

Figure 2. $a-b$ : Emergency X-rays, patient 2.

Since all three patients suffered from soft tissue injuries to the proximal tibia, ranging from grade $\mathrm{Cl}$ (superficial abrasion, figure 3) to grade C2 (deep abrasions, impending compartment syndrome), decision was made to perform a definitive fixation with hybrid tibio-tibial external fixator (TenXor Stryker, figure 4a-c).

This strategy allowed the management of the soft tissue injuries without any complications, during and after the procedure. The post-operative mobilization protocol allowed immediate knee mobility and full weight bearing. The patients remained in the orthopedic ward for an average of 12 days before being transferred to rehabilitation. Outpatient X-ray were performed at 6 weeks and 3 months postoperatively, finding no cut-through of the proximal tibia wires. There has been no pin tract infection. External fixator removal procedures were undertaken for two patients at 3 months and one patient at 6 months. Standard X-ray views 6 months after external fixation showed that complete consolidation had been achieved (figure $5 a-b$ and figure $6 a-b$ ).

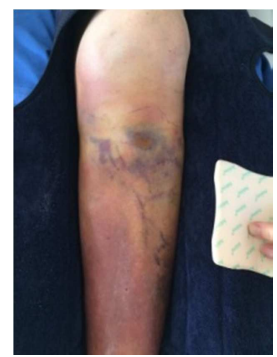

Figure 3. Superficial abrasions and contusion of soft tissues (grade C1, patient 2).
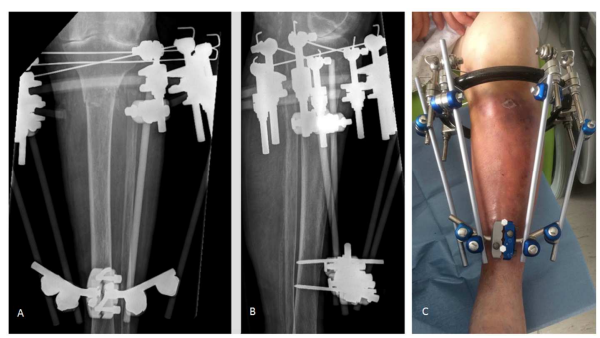

Figure 4. $a-b$, Postoperative X-rays (patient 2), c, TenXor external fixation system.

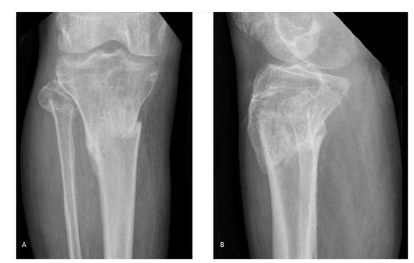

Figure 5. $a-b$ : X-rays at 6 months (patient 1).

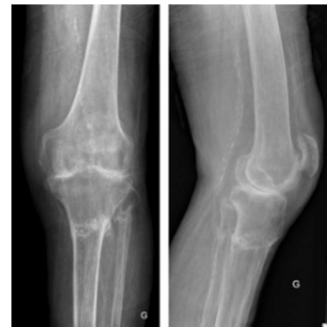

Figure 6. $a$-b: X-rays at 6 months (patient 2). 
At six months of follow-up, knee flexion beyond 90 degrees was possible in all three patients. All of them were able to walk with the help of crutches. Regarding social function and mobility, scores ranged from 4 to 7 on the assessment of Parker and Palmer (ability to walk inside the house without any help and go shopping using crutches) (Table 2).

Table 2. Clinical results and living places at six months follow-up.

\begin{tabular}{llll}
\hline & Patient 1 & Patient 2 & Patient 3 \\
\hline Range of motion (flexion/extension) & $90-10-0$ & $100-5-0$ & $100-0-0$ \\
Preoperative Parker and Palmer score & 4 & 4 & 9 \\
Postoperative Parker and Palmer score & 4 & 4 & 7 \\
Ability to walk & With crutches & With a walking frame & Without any help inside the house \\
Living place & Home & Retirement Home & Home \\
\hline
\end{tabular}

\section{Discussion}

The main purpose of treatment for proximal extra-articular tibial fracture is to restore the length, rotation and axis of the tibia. Secondary objectives are to prevent secondary displacement of the bone fragments and to avoid soft tissue complications. Plate fixation allows an optimal visualization of the fracture site, and thus a direct and anatomical reduction. However, it often requires extensive soft tissue dissection, and therefore increases the risk of wound dehiscence which may lead to infection [16-20]. The rate of deep infection following dual plating osteosynthesis of proximal tibial fracture with an articular extent rose up to $88 \%$ in the series reported by Young [16]. On the other hand, intramedullary nailing is much less invasive but has been shown to be particularly technically difficult $[21,22]$. Indeed, high incidences of proximal tibia malreduction after nailing have been reported in the literature, and a valgus deformity is commonly described as well [23, 24]. Lang et al [22] documented $56 \%$ of valgus deformity following an intramedullary nailing, in a study of thirty-two extraarticular fracture of the proximal third of the tibia. Because early knee motion is mandatory for postoperative recovery, specific external fixation systems have gradually found their place in the range of possible treatment options [25]. Devices such as Ilizarov circular frame has been developed in order to allow initial weight bearing without compromising skin condition [26]. The three cases of proximal tibia fractures described above suffered from several co-morbidities, with varying degrees of associated soft-tissue injury. Choosing external fixator as a definitive treatment prevented the occurrence of secondary soft tissue trouble. Skin healing was indeed achieved without any complications in all cases, and no pin tract infection were reported. Several authors suggest that the use of external fixator devices leads to lower rates of deep infections [27-29]. Ariffin et al recommended to use hybrid external fixation in the treatment of complex high energy proximal tibia fractures, providing adequate fracture stabilization and protection of soft tissue healing to achieve consolidation [27]. Furthermore, this technique has a limited operating time, which is not negligible in elderly patients. It is obvious that external fixation is at risk of compromising the quality of the reduction, but the consequence on the functional outcome remains uncertain [30]. A meta-analysis comparing open reduction internal fixation and external fixation have found that the return to pre-injury activities may be faster in patients undergoing external fixation, even though there was no difference at 24 months follow-up [20]. As rapid functional recovery is a primary objective in patients with limited life expectancy, and this seems to give a major advantage to the external fixation technique. Also, there was no statistically significant difference in the risk of deep infection, compartment syndrome, thrombosis or range of motion between the two surgical techniques $[20,31]$.

\section{Conclusion}

To date, there is no gold standard for the treatment of proximal tibia fractures associated with soft tissue injuries in the elderly population. The three cases described above, all managed with an external fixation technique followed by immediate full weight bearing, achieved a satisfying functional result and a complete tibial consolidation at six months postoperatively, without compromising skin healing. In this way, hybrid tibio-tibial external fixator as a definitive fixation technique may be a valid surgical option in the treatment of these fractures, resolving adequately the problem of soft tissues healing, and offering an acceptable functional outcome for low demand patients.

\section{References}

[1] Amin S, Achenbach SJ, Atkinson EJ, Khosla S, Melton LJ. Trends in Fracture Incidence: A Population-Based Study Over 20 Years. J Bone Miner Res. March 2014; 29 (3): 581-9.

[2] Lang G, Cohen B, Bosse M, Kellam J. Early primary total knee replacement for complex proximal tibia fractures in elderly and osteoarthritic patients. Clinical Orthopaedics and Related Research. June 1995; (315): 64-74.

[3] Chen F, Huang X, Ya Y, Ma F, Qian Z, Shi J, et al. Finite element analysis of intramedullary nailing and double locking plate for treating extra-articular proximal tibial fractures. J Orthop Surg Res. January 2018; 13.

[4] Brooks SE, Peetz AB. Evidence-Based Care of Geriatric Trauma Patients. Surg Clin North Am. October 2017; 97 (5): 1157-74.

[5] Wennergren D, Bergdahl C, Ekelund J, Juto H, Sundfeldt M, Möller M. Epidemiology and incidence of tibia fractures in the Swedish Fracture Register. Injury. November 2018; 49 (11): 2068-74. 
[6] Kandemir U, Herfat S, Herzog M, Viscogliosi P, Pekmezci M. Fatigue Failure in Extra-Articular Proximal Tibia Fractures: Locking Intramedullary Nail Versus Double Locking Plates-A Biomechanical Study. Journal of Orthopaedic Trauma. February 2017; 31 (2): e49-54.

[7] Lee S-M, Oh C-W, Oh J-K, Kim J-W, Lee H-J, Chon C-S, et al. Biomechanical Analysis of Operative Methods in the Treatment of Extra-Articular Fracture of the Proximal Tibia. Clin Orthop Surg. 2014; 6 (3): 312.

[8] Zhang J, Ebraheim N, Li M, He X, Liu J, Zhu L, et al. External Fixation Using Femoral Less Invasive Stabilization System Plate in Tibial Proximal Metaphyseal Fracture. Clin Orthop Surg. March 2015; 7 (1): 8-14.

[9] Vermeire J, ScheerLinck T. Early primary total knee replacement for complex proximal tibia fractures in elderly and osteoarthritic patients. Acta orthopaedica Belgica. 2010; 76 (6): 785 .

[10] Zura R, Mehta S, Della Rocca GJ, Steen RG. Biological Risk Factors for Nonunion of Bone Fracture. JBJS Rev. May 2016; 4 (1).

[11] Kortram K, Bezstarosti H, Metsemakers W-J, Raschke MJ, Van Lieshout EMM, Verhofstad MHJ. Risk factors for infectious complications after open fractures; a systematic review and meta-analysis. Int Orthop. 2017; 41 (10): 1965-82.

[12] Hernlund E, Svedbom A, Ivergård M, Compston J, Cooper C, Stenmark J, et al. Osteoporosis in the European Union: medical management, epidemiology and economic burden. Arch Osteoporos. 2013.

[13] Müller ME, Nazarian S, Koch P, Schatzker J. The Comprehensive Classification of Fractures of Long Bones. Springer Science \& Business Media; 2012. 235 p.

[14] Ibrahim DA, Swenson A, Sassoon A, Fernando ND. Classifications In Brief: The Tscherne Classification of Soft Tissue Injury. Clin Orthop Relat Res. February 2017; 475 (2): $560-4$.

[15] Tscherne H, Oestern HJ. A new classification of soft-tissue damage in open and closed fractures. Unfallheilkunde. March 1982; 85 (3): 111-5.

[16] Young MJ, Barrack RL. Complications of internal fixation of tibial plateau fractures. Orthop Rev. February 1994; 23 (2): 149-54.

[17] Mallik AR, Covall DJ, Whitelaw GP. Internal versus external fixation of bicondylar tibial plateau fractures. Orthop Rev. December 1992; 21 (12): 1433-6.

[18] Moore TM, Patzakis MJ, Harvey JP. Tibial plateau fractures: definition, demographics, treatment rationale, and long-term results of closed traction management or operative reduction. $\mathrm{J}$ Orthop Trauma. 1987; 1 (2): 97-119.
[19] Dillin L, Slabaugh P. Delayed wound healing, infection, and nonunion following open reduction and internal fixation of tibial plafond fractures. J Trauma. December 1986; 26 (12): 1116-9.

[20] Metcalfe D, Hickson CJ, McKee L, Griffin XL. External versus internal fixation for bicondylar tibial plateau fractures: systematic review and meta-analysis. J Orthop Traumatol. December 2015; 16 (4): 275-85.

[21] Freedman EL, Johnson EE. Radiographic analysis of tibial fracture malalignment following intramedullary nailing. Clin Orthop Relat Res. June 1995; (315): 25-33.

[22] Lang GJ, Cohen BE, Bosse MJ, Kellam JF. Proximal third tibial shaft fractures. Should they be nailed? Clin Orthop Relat Res. June 1995; (315): 64-74.

[23] Tejwani N, Polonet D, Wolinsky PR. Controversies in the Intramedullary Nailing of Proximal and Distal Tibia Fractures: Journal of the American Academy of Orthopaedic Surgeons. October 2014; 22 (10): 665-73.

[24] Hiesterman TG, Shafiq BX, Cole PA. Intramedullary nailing of extra-articular proximal tibia fractures. J Am Acad Orthop Surg. November 2011; 19 (11): 690-700.

[25] Zhao X, Ma J, Ma X, Jiang X, Wang Y, Li F, et al. A meta-analysis of external fixation versus open reduction and internal fixation for complex tibial plateau fractures. International Journal of Surgery. March 2017; 39: 65-73.

[26] Santy J, Vincent M, Duffield B. The principles of caring for patients with Ilizarov external fixation. Nursing Standard. March 2009; 23 (26): 50-5.

[27] Ariffin HM, Mahdi NM, Rhani SA, Baharudin A, Shukur MH. Modified hybrid fixator for high-energy Schatzker V and VI tibial plateau fractures. Strategies Trauma Limb Reconstr. April 2011; 6 (1): 21-6.

[28] Catagni MA, Ottaviani G, Maggioni M. Treatment strategies for complex fractures of the tibial plateau with external circular fixation and limited internal fixation. J Trauma. November 2007; 63 (5): 1043-53.

[29] Ali AM. Outcomes of open bicondylar tibial plateau fractures treated with Ilizarov external fixator with or without minimal internal fixation. Eur J Orthop Surg Traumatol. April 2013; 23 (3): 349-55.

[30] Marsh JL, Buckwalter J, Gelberman R, Dirschl D, Olson S, Brown T, et al. Articular fractures: does an anatomic reduction really change the result? J Bone Joint Surg Am. July 2002; 84 (7): $1259-71$.

[31] Berven H, Brix M, Izadpanah K, Kubosch EJ, Schmal H. Comparing case-control study for treatment of proximal tibia fractures with a complete metaphyseal component in two centers with different distinct strategies: fixation with Ilizarov frame or locking plates. J Orthop Surg Res. May 2018. 